\title{
SCIENCE.-Supplement.
}

FRIDAY, APRIL 8, 1887.

\section{EFFECTS OF EXPLOSIONS ON THE EAR.'}

THAT the ear may be injured by the violence of aerial impact, or concussive force, propagated by the explosion of gunpowder, has been known ever since the introduction of explosives in military warfare. Owing, however, to the obscurity of traumatic lesions of the drum of the ear, or of its deeper parts, and the limited means of observation at the command of the military surgeon in the field, it has been more difficult to study these injuries than most other wounds. Such was my own experience, at least; and reference to the literature of the subject shows that the opportunities of writers on military surgery were probably no greater in this respect. It is a fact, moreover, that from the suffering occasioned by other and more painful wounds simultaneously received, together with the bewilderment caused by nervous shock, aural injuries are liable to be entirely overlooked. Indeed, in some of the cases about to be described, there were serious wounds of the ear, of which the wounded men themselves had been unconscious up to the time of my examination, several weeks after the accident. It may be stated here, on the contrary, that after artillery engagements it is not unusual for participants to fancy that deafness, due to other causes wholly, has been produced by the loud sounds of great guns; and, since the war of the rebellion, applicants for pensions not infrequently present their cases with the statement that aural disability has originated in this manner.

While the writer was recently seeking information from persons having had experience in the field or on shipboard, especially among army and navy officers, an opportunity quite unexpectedly presented itself to investigate thoroughly the effects of concussive force on the ears of a number of men in the midst of whom a twelve-inch mortar-shell, weighing five hundred and eighty-five pounds, and containing a bursting charge of twenty-seven pounds of rifle-powder, was accidentally exploded. This took place at the U. S. ordnance proving-ground, Sandy Hook, Oct. 21, 1886 , at 3.30 P.M.

The scene of the catastrophe, as shown in fig. 2,

1 Condensed from the Medical record of Feb. 19, 1887, with illustrations reproduced by permission of $\mathrm{Wm}$. Wood \& Co. was reproduced from a photographic view taken on the spot by my friend Mr. Walter C. Tuckerman. The men were taken in about the same positions they occupied at the time of the accident. The places of three of them-namely, Lieutenant Medcalfe and Private King, killed, and Corporal Goodno, absent in hospital - were occupied by other persons.

The diagram of the twelve-inch mortar, guncarriage, and platform (fig. 1), where the firing was taking place, was kindly designed by Captain Whipple. The facings of the men are designated by arrows, and the direction and force of the wind at the time are also shown. The distance of the men from the shell which exploded was as given below :-

\begin{tabular}{|c|c|c|c|c|c|}
\hline \multirow{2}{*}{\multicolumn{6}{|c|}{$\begin{array}{l}\text { A. Sergeant Abbott, position } 8 \text { feet from the shell. } \\
B \text {. Private King, }\end{array}$}} \\
\hline & & & & & \\
\hline C. Lieutenant Medcalte, " & & & & & \\
\hline D. Corporal Clark, & & tee & on & $\mathrm{he}$ & \\
\hline$E$. Corporal Goodno, & 12 & 6 & 66 & 66 & \\
\hline$F$. PrivateCunningham," & 15 & "6 & 6 & 66 & \\
\hline G. Private Cramer, & 15 & "6 & "6 & 66 & \\
\hline H. Mr. Sinclair, & 19 & “ & 6 & 66 & \\
\hline I. Private Burns, & 19 & “ & 6 & 66 & \\
\hline$J$. Corporal Ingram, & 16 & “ & 66 & 6 & \\
\hline
\end{tabular}

Sergeant Abbott was blown ten feet from his position; Private King (who was closing the screw plug in the base of the shell with a drift and hammer, and thus exploded it) was instantly killed, and his body was blown fifty-five feet away ; Lieutenant Medcalfe, who wasstanding by the side of the shell, was blown twenty-two feet, and died in thirty minutes; Private Clark was blown fifteen feet. The other six men kept their feet during the explosion. Eight men thus escaped with their lives, but all of them were more or less injured by the concussion, and some of them received contused wounds or were burned by the blast.

As might have been expected, the immediate effect of the severe concussion caused by the blast of the explosion just described was dumfounding in the extreme, so far as most of the persons in the immeaiate vicinity were concerned. The mental confusion which ensued in some of the cases lasted a long time, and in one instance, that of Corporal Clark, it is doubtful if complete recovery ever takes place.

In some of the cases the absence of prominent symptoms of injury of the ear, such as pain in the organ, tinnitus, deafness, or discharge, was noticeable. Soldiers are, however, as a rule, accustomed to endure hardship without complaint, and, in 
fact, all insensitive persons are liable to overlook ear-disease until incapacitated to perform their work. It was only after persistent inquiries in each one of the cases reported was dependent on the distance from the shell, the facing at the moment of explosion, and the size of the external

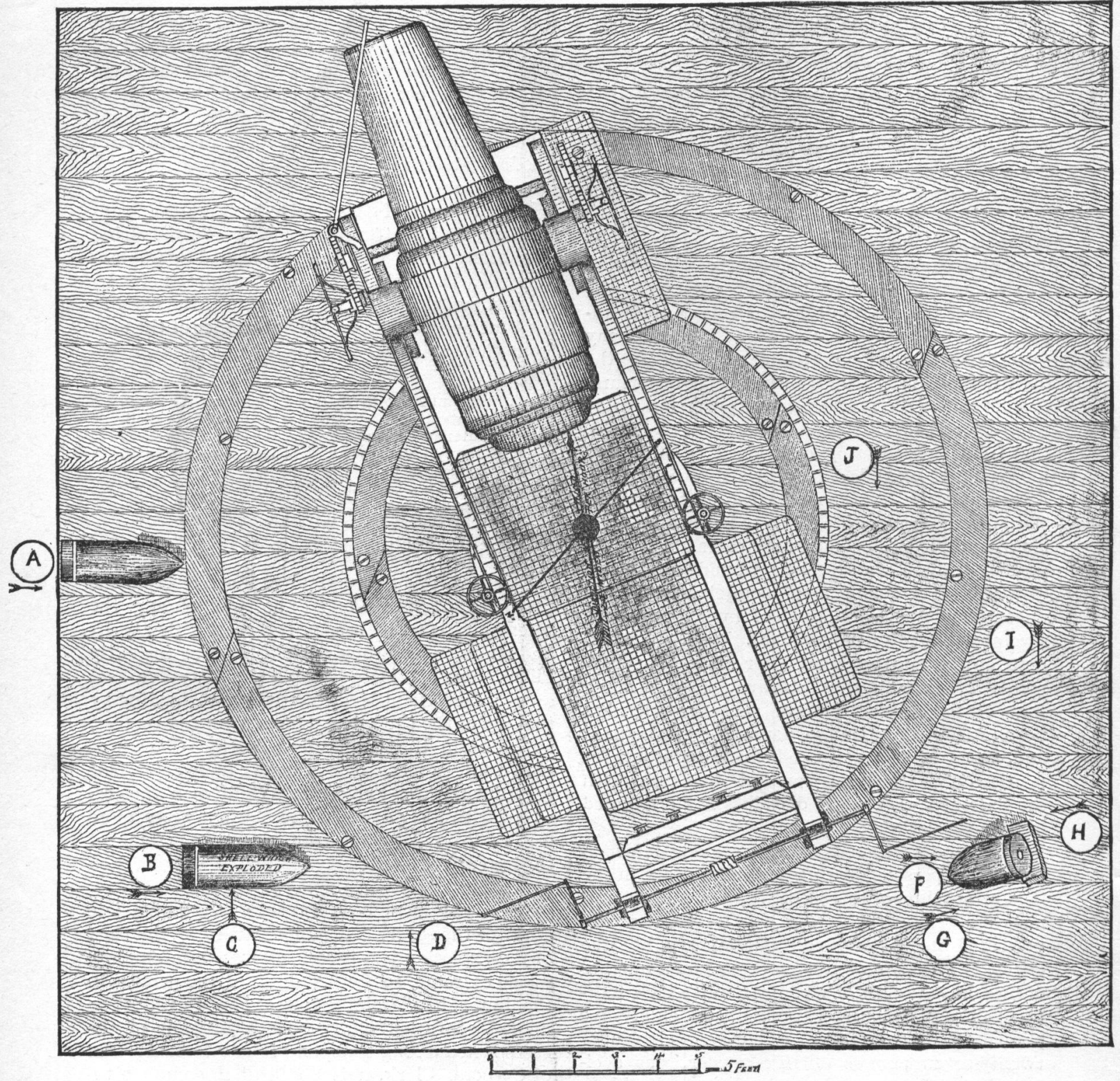

Fig. 1.

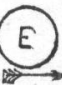

were made that some of these persons would admit that they had suffered any injury of the ear.

The extent of the injury of the drum of the ear auditory canal. In some instances, as, for example, in the cases of Abbott, Clark, Goodno, Ingram, and Sinclair, the drum-heads were driven in with 
such force as to cause their complete destruction by death of the tissues. In some of the cases it will be observed that partial or entire reproduction of the drum-head took place. The spontaneous cure, in most of these cases, without leaving any discharge, affords a valuable suggestion in the treatment of inflammation of the ear, as well as in operations on the organ, in healthy persons. It is believed, notwithstanding the great destruction of the membrana tympani, that the chain of ossicles has been left in every case. It is fortunate for man that great augmentation of tension, exerted either from without or from within,
Connecticut, ' discharge of cannon '............ 1

Georgia, ' firing cannon in war'.................

Indians, "cannon fired' $. . . . . \ldots \ldots \ldots \ldots \ldots \ldots . \ldots 1$

Illinois, 'gunshot wound '...................... 1

Massachusetts, 'discharge of cannon'........... 1

Minnesota, 'from a shot '..................... 1

Missouri, 'Jar from cannon'............... .1

Nebraska, ' heavy cannonade in France'......... 1

New York, 'report of gun'.................. 1

Ohio, 'discharge of cannon' .................. 1

"6 'severing of tongue cords by shot'........ 1

Pennsylvania, 'shot of gun '................... 1

Texas, 'gunshot wound '...................... 1

" 'gun fired close to ear'.................. 1

Wiscousin, 'firing cannon '..................... 1

Total............................. $\overline{15}$

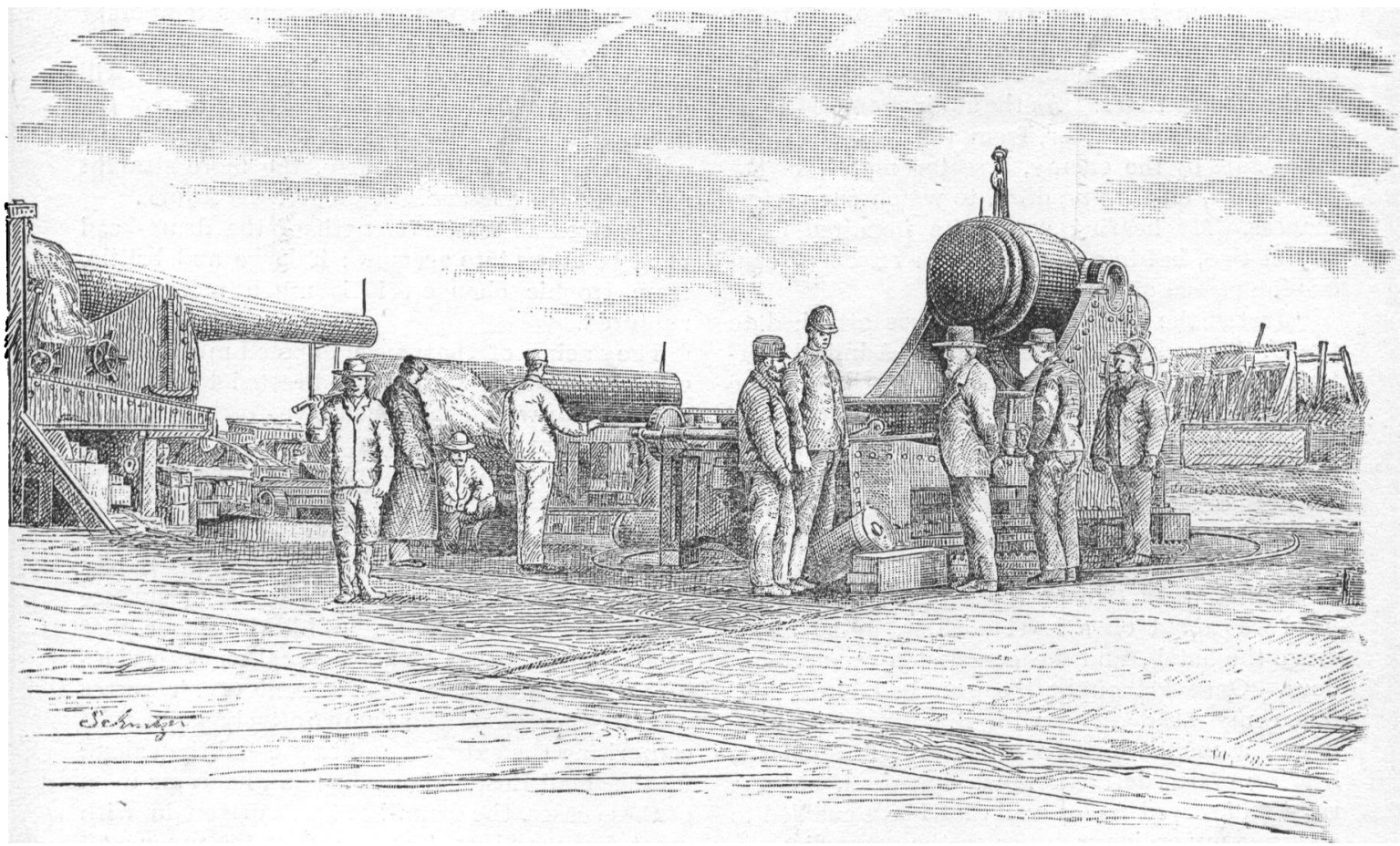

FiG. 2.

upon the transmitting mechanism of the ear, may be experienced without serious injury to the stapes or labyrinth.

I have endeavored to obtain some reliable statistics in regard to the frequency of injuries to the organ of hearing during the late war of the rebellion, but without satisfactory results: thus, the number reported by the census-takers in 1880 , as furnished me by Mr. Fred. A. Wines of the census bureau, was only fifteen from all causes. These are given below. The meagreness of facts obtained in this manner illustrates the inefficiency of such a method for collecting valuable information. A single shell-explosion has, in many instances, doubtlessly injured as great a number.
The pension-office, doubtless, might furnish more reliable statistics were the disabilities for which pensions were granted tabulated ; but congress has, as I am informed by Medical Examiner Wood, omitted to make any appropriation for such work. It is to be regretted that more attention has not been given to this matter, since there must be a large number of persons who have suffered injury to the ears from the concussion of explosives, who are as much entitled to be pensioned by the government from this cause as from others which happen to be more easily diagnosed.

I have obtained some facts, in conversing with officers who served during the war of the rebellion, which may be of interest. Commander 
Robeson, at the naval attack on Fort Fisher, found that the continued explosion of fifteen-inch shell at close quarters gave rise to very disagreeable ringing in the ears, which finally benumbed the hearing sense so much that he could not hear an order given on deck for several days : the disability, however, was but temporary.

I am in receipt of a communication from Medical Director Henry O. Mayo (retired), U.S.N., giving his own experience as to the effect on the ear of the concussion of great guns, which is of much interest, since it shows the effect of repeated injuries. He says, "I first felt the effects of concussion from big guns the summer of 1861, on board the frigate Savannah, while engaged in a scrimmage with some rebel gunboats at the mouth of the James River. As the affair promised to be of a bloodless character, from the respectful distance kept by the enemy, I seated myself in the bridle-port, on the gun deck, to watch the performances. My hearing was quite impaired for a day or two, but in a short time the effects of concussion passed off entirely.

"Just at the close of 1864, I was attached to the U. S. steamship Powhattan, of Admiral Porter's fleet, and was engaged five days (three at one time and two at another) in the bombardment of Fort Fisher and the other batteries at the entrance to Wilmington. Having occasion to go on deck at times during the action, I could only do so by the cabin companion-way, which was but a few feet from the eleven-inch pivot gun. This chanced to be discharged two or three times, just as my head was about on a level with it, going up or down the hatch, and the concussion was tremendous. Once I thought the gun had burst, and taken my head along with it. Upon reaching home, a month or two afterward, I found the hearing of the left ear much impaired, but the right still served me so well that I was enabled to continue my ordinary duties on the active list.

"In the early part of 1870 I went to China as surgeon of the Asiatic fleet. During this cruise I was exposed for one entire day to the concussion of big guns engaged at target-firing on board the flagship Colorado. This gave the coup de grace to the hearing of the left ear, and still further impaired that of the right. In $1875 \mathrm{I}$ was retired on account of deafness."

Dr. Mayo is of the belief that the cause of the defectiveness lies in the transmitting mechanism of the middle ear, and not in the inner ear, or auditory nerve-tract. The Eustachian tube of the left (worst) ear has always seemed abnormally pervious, while the right was considerably obstructed. He cannot hear the loudest-ticking watch pressed against the left ear, and only faintly in the right. He can converse pretty well with one person, at close range, who speaks slowly and distinctly.

In general, it may be said that the concussion of great guns is much less in the rear of the piece than just over it or at one side, and that the more in advance, the greater the exposure to the blast. On shipboard a gun's crew is usually stationed from four to eight feet to the rear of the muzzle, and, when protected by bulwarks and decks, experience no special inconvenience; but, if the ear happens to be on the same plane as the face of the muzzle, the effect at a distance of a few feet is disagreeable, or even painful, and causes temporary deafness.

The force of impact upon the drum-head will depend somewhat on the size and curvature of the external auditory canal and the rigidity of its cartilaginous walls: of course, the more straight and large the passage, the greater the injury.

The size and tensile strength of the drum-head must be taken into account: if large and brittle, from trophic changes, it is much more easily ruptured.

The facing of the person exposed must also be considered : usually the ear directed toward the object from which the concussive force is propagated suffers most; but. in the case of Ingram it was otherwise, the sound-waves having been reflected.

The immediate effect of the blast-impact in the cases injured by the shell-explosion at Sandy Hook was undoubtedly upon the exterior surface of the drum-head mainly. While it is true that atmospheric tension is almost equal on both sides of the drum head, yet a current of air passes much faster along the comparatively large tube comprising the external auditory canal than along up the small Eustachian tube ; and hence, in most of these cases, the drum-head was driven in with great force, and contused against the inner wall of the tympanum and the retained air. The effect of such violent concussion is to cause the death of the membrane.

The momentum of sound-waves may ordinarily be estimated by the application of the law of central forces, the force being inversely to the square of the distance. The effects, practically, of such intense concussive force, however, cannot be measured by rules governing sound ordinarily, since it has been found by experience, that, instead of finding himself surrounded near the breech of the gun by highly rarified air, the experimenter may be subjected to quite an opposite condition; namely, one of condensation. In the former, intra-tympanic air would rush outwardly, carrying the drum-head before it. In confirma- 
tion of this allegation, the puzzling experience related to me by Captain Shaler may be cited : "The window-glass of the officers' quarters, at the testing-grounds at Sandy Hook, situated some three to five hundred feet to the westward of the gun park shown in the picture, are liable to be shattered by the concussion of large pieces in practice, and it has been found that the glass is forced outward at one time, and inward at another." Regarding the drum-heads as window-glass under like conditions, we might find them ruptured by compression from without in one instance, and by distention of intra-tympanic air in another.

All of us are aware of the difficulty of ascertaining the source of sound in a sea-fog, where vapor-tension varies in a much greater degree than inland. Professor Henry described the reflections of sound which here take place as 'acoustic shadows,' - a picturesque comparison, recognizable by every one familiar with those similar phenomena, namely, the reverberatory detonations of thunder during a storm, where clouds or mountain-peaks intervene. It is to the unrecognizable 'vapor-peaks' that many unexplained and puzzling acoustic manifestations are due. In the case of Corporal Ingram, cited, the wave from the blast did not nearly so much affect the right ear, which was turned toward the shell, as the left one, the scund having been apparently deflected from its course by the heavy gun-carriage intervening.

Experiments are wanting to determine the windage $^{1}$ of balls. This must depend on their size and velocity, nearness of passage, and the force and direction of the wind. There seems to be no doubt but that the windage of a cannonball might rupture the drum-head of the ear. The compression of the air before and around the ball, I am informed by my friend Prof. A. M. Mayer, is considerable ; and the velocity of the compression is equal to that of the ball, which velocity may even exceed that of wind itself. So an aerial blow of such a mass of air, at such high velocity, is probably quite sufficient to rupture the drumhead.

The size and force of modern military explosives having been greatly increased of late years, much more injury to the ear is likely to occur in future than has been recorded of the past, though the number of accidents from premature discharge, or from exposure to the blast in firing breech-loading

1 'Windage', it should be said, is a technical term used in military parlance to indicate the difference in diameter between the bore of a gun and its projectile. The wo d has been, perhaps improperly, adopted by writers on military surgery, in which sense it refers to the impact of the condensed air surrounding a missile passing near any part of the body. pieces, must be less than when muzzle-loaders were in vogue.

It is the experience of many officers that the vibrations of great intensity which are given off from some field-pieces and bursting shells, charged with high explosives, are more disagreeable than the heavier sounds of great guns. The metal itself vibrates under these circumstances similarly to a tuning-fork.

A very disagreeable jar is imparted to the temporo-maxillary articulation when the individual is near a great gun being fired off. This is lessened, it is believed, by standing on the toes and leaning forward. Some simple precaution, to be employed by officers and men during artillery practice, would seem very much needed, since aural shock is not only painful and distressing, but orders cannot be well heard while the confusion lasts.

There is probably no better protection than a firm wad of cotton-wool well advanced into the external auditory canal. In suggesting this protection, it is believed that harm can seldom take place from pressure of air from within, since it is known that the violent introduction of air into the tympanum from the throat, by means of Politzer's method of inflation, seldom ruptures the drumhead; though, if such a volume of air were suddenly driven into the external auditory canal, the drum-head would in nearly all cases be ruptured.

The writer, in finishing this account of the aural injuries done by the explosion, would request that other observers having experience in this direction kindly communicate with him. Any knowledge that may thus be contributed would be of service to military surgeons, otologists, and otbers.

Samuel Sexton, M.D.

\section{MINING INDUSTRIES AND MINERAL RE- SOURCES OF THE UNITED STATES.}

Tenth census of the United States. Vol. xv.: Report on the mining industries of the United States (exclusive of the precious metals). By Raphael Pumpelly. Washington, Government. $4^{\circ}$.

THIS report supplements those previously issued on the precious metals, and on petroleum, coke, and building-materials; and these volumes together constitute a very complete account of the mining and quarrying industries of the country for the census-year.

The appearance of this volume, nearly twothirds of a decade after the close of the censusyear, is neither timely, nor creditable to those responsible for the delay ; for the practical interest and usefulness of works of this class, except, perhaps, for students of economics, diminish rapidly 